\title{
Why Are Rural People Vulnerable to Famine?
}

\section{Jeremy Swift*}

It is now generally accepted by researchers (although not by governments) that famines are caused as much by act of man as by act of god. But our understanding of famine is still quite rudimentary, and what little we know is rarely translated into policies to prevent or control famine. Few people would argue that we clearly understand what makes people vulnerable to famine, or that we can predict that one group will be vulnerable while another will not.

It is not even clear, when different people talk about famine, that they are talking about the same thing. Those who suffer from famine have a more exact vocabulary than those who analyse it. Turkana herders in northern Kenya distinguish 'years in which people died' from years of less severe shortage (Swift 1985). In Darfur, the former contingency is known as 'famine that kills' (de Waal 1987) and in Hausaland, northern Nigeria, as the 'great hunger' (Watts 1983), to distinguish it from events in which there is hardship but no large-scale mortality. Social and economic analysts on the other hand, tend to lump all major food shortages together as famine, and populists use the term for any general shortage of a desirable good, as in 'book famine'.

There is even some doubt about what exactly a famine is. Famine is traditionally seen as a food or subsistence crisis, resulting from an absolute shortage of food, or an inability by some groups to gain access to food. Recently however, de Waal (1989) has put forward a 'health crisis model' to replace this 'starvation model', arguing that most modern African famines, especially Darfur in 1985-6 are in fact crises of epidemiology and susceptibility to disease, caused only indirectly - if at all - by a food crisis. I will assume here, without making the point in detail, that health crises and food crises are in fact closely related, indeed that a more general crisis - a social and economic crisis - is involved. I assume that the danger of famine is of a sudden, catastrophic and prolonged consumption deficit, accompanied by a surge in disease, and by major social and economic disruption. The order in which these occur and their relation to each other is an urgent current research priority, but it is not the subject of this article. Here I use consumption deficit as a proxy for this complex of dislocations.

Vulnerability is not simply another word for poverty. Poor people are usually among the most vulnerable, but understanding vulnerability means disaggregating poverty. Landless labourers and people in informal urban service trades, whose income in most years may be as high or higher than poor farmers, are often more vulnerable than the latter to a drought or other disruption of the rural economy. Sharecroppers or even bonded labourers may be less well off most of the time than small farmers, but have a better guarantee of a subsistence minimum in bad years. Small pastoralists may have a reasonable cash income and high nutritional standards most of the time, but are especially vulnerable to disruptions of the livestock market or to epidemic animal disease.

In this article I analyse what makes people vulnerable. This involves a further distinction between two levels or categories of causation of famine. I distinguish here between the proximate or intermediary variables, which are the direct links to famine, and the indirect or primary factors, which are the more general ecological, economic or political processes determining whether communities thrive or decline. Drought, animal or plant disease, urban bias, agricultural pricing policy, civil war and many others are primary factors in determining vulnerability, but they act in different and often complex combinations through three proximate factors: production, 
exchange and asset processes. It is the role of these proximate variables that is described here, since they offer a way of classifying and understanding how vulnerability is created and maintained, and possibly how it can be reduced.

\section{Production failures}

Our first understanding of famine was that it is caused mainly by production failures. We may picture this as a simple cause and effect chain as follows:

\section{Diagram 1}

\section{PRODUCTION}

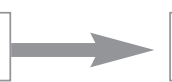

CONSUMPTION

Factors which act on the production box, and which can lead to consumption failure, include drought, flood, or animal and plant disease. Vulnerability is increased or decreased by general ecological potential (low potential leads to low and variable production and thus to higher risk of production and consumption failure), technology, crops and cropping strategies, and the possibility of alternative incomegenerating strategies. In this production-based view, famine vulnerability is mainly the result of uncertain production, and famine is directly caused by production failure, due for example to drought (the African famines of the 1910s, 1970s and 1980s), to animal disease (the African famines of the 1890s, following a rinderpest pandemic), to plant disease (the Irish potato famines), or even to the refusal of farmers to cultivate (one official view of the Ukrainian famine of the 1930s).

\section{Exchange failures}

Building on the insights of the Indian famine commissioners since the 1860s, Amartya Sen showed in a classic book, Poverty and Famines (Sen 1981), that famines could, and often did, take place where there was no production failure, or where food was readily available. He identified failures in the exchange or market mechanisms as a key cause of famine among poor people. Sen argued that the value of poor people's production activities or endowments - their labour, cash crops, or animals - is liable to collapse in relation to staple food prices. When this happens, poor people starve, not because there is no food available (the production failure view), but because they cannot afford to buy food: the wage labour rate or the value of their animals or cash crops is too low in relation to food prices for them to acquire enough calories. We may think of this as a failure in terms of trade, or an exchange rate failure. Sen's case histories show that exchange rate failures of this sort are an important trigger for famine in Africa and Asia.

The two main sources of terms of trade vulnerability for the rural poor are the wage labour market and commodity markets for agricultural and pastoral products. We may add these to the diagram of the famine causal chain.

\section{Diagram 2}

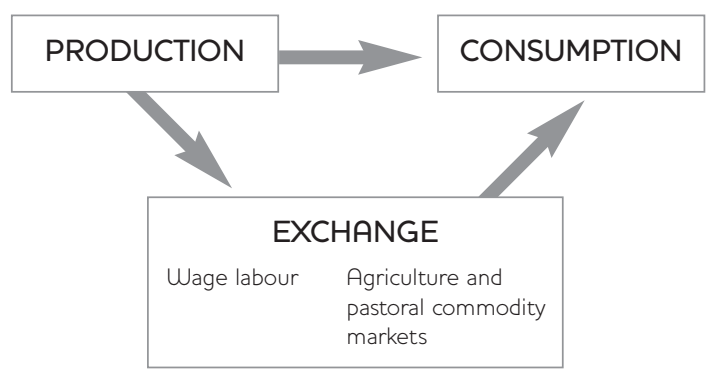

Sen's analysis identified some important sources of vulnerability. He showed for example that, especially in South Asia, agricultural wage labourers and people in small-scale service trades are particularly vulnerable because of the sensitivity of their wage rates to changes in the wider economy. In Africa, with the possible exception of Sudan, this is not so much the case because of the much smaller proportion of people in such employment: African casual and informal sector urban wage labour markets seem less volatile and immediately responsive to external shocks and production crises such as droughts. In Sudan however, variability in seasonal agricultural wage labour rates is an important source of vulnerability.

On the other hand, in Africa it is the pastoral economies that form a major population group vulnerable to terms of trade failures. African pastoralists now get a large part of their subsistence through market exchanges or barter deals. West African pastoralists almost all get more than half their total calorie intake in cereal form, acquired by the sale or barter of animals or animal products. In Sudan and East Africa, the proportion is more variable, with some pastoral groups still heavily dependent for calorie intake on milk, meat and sometimes blood produced within the household, although even these groups depend much more on 
cereal markets in bad years. Pastoral terms of trade under normal circumstances mean that calories of animal origin are considerably more expensive (usually in the range of two to five times more) than calories of vegetable origin. This means that pastoralists can usually get cereals at a substantial discount in exchange for animal products through the market.

It does however make pastoralists especially vulnerable to change in the normal animal-to-cereal price ratios. If animal prices fall (because animals are in poor condition, or many herders are selling, or few people want to buy), pastoralists face an exchange crisis even if the price of cereals does not rise, although the same forces that bring down animal prices are likely to push up cereal prices. All recent African famines in pastoral areas have been characterised by this price scissors effect. Of course, such failures in the exchange box in the diagram above are compounded by failures in the production box. Often the same events - drought or animal disease - trigger failures in both boxes at once, with a synergistic effect on consumption patterns.

Sen's analysis has made a major contribution to our ability to understand how famine works, and by focusing attention on exchange or terms of trade relationships helps identify the people and communities most vulnerable. But it leaves several important questions without an answer:

- Although exchange rate failures can be an important famine trigger, in fact they do not help very much in understanding or predicting the timing of the onset of the sudden collapse in people's ability to feed themselves, and they offer very little explanation of the apparent cumulative vulnerability of some communities. The breakdown in a community's ability to provide for itself, or in the ability of some members to provide for themselves, often happens some time after the failure of exchange or terms of trade relationships, just as it may occur one or two years after the onset of drought. Indeed the collapse sometimes takes place when the production and exchange situations appear to be improving. It seems as though there is a threshold of individual and community impoverishment, not immediately explained by production or exchange factors, at which the ability of households or communities to survive collapses. In a wider sense, the explanation is an ahistorical one, unable to cope with changing vulnerability over time except by pointing to changing exchange or terms of trade risk. In fact, Sen's analysis treats each crisis as a new event, unrelated to earlier or later crises.

- Sen does not adequately explain the differential vulnerability within some communities or between similar communities apparently facing similar production or exchange failures. Two examples will illustrate this: (a) in the West African Sahel, some pastoral communities such as the Tuareg are divided into ethnically stratified groups of free people and former slaves; these groups may now be equally poor, but they do not seem to be equally vulnerable to famine; (b) refugees in camps near capital cities (e.g. Khartoum) are not as vulnerable as refugees in rural camps (e.g. in south Kordofan or Darfur), even though the former have no more resources than the latter, and are equally affected by exchange failures.

- Sen's work has the virtue of focusing on the differential role of poverty within communities, but has problems as an analytic tool since it looks mainly at households; it does not help very much in analysing differential vulnerability between individuals within households, nor to certain aspects of vulnerability of entire communities.

- The work does not help us understand apparent differences between communities in their expectations of government assistance. Ethiopian villagers apparently readily move to the roadside or to administrative centres in times of crisis; Sudanese villagers in Darfur and most Sahelian pastoralists do not. Such differences are an important part of vulnerability and are also crucial to planning a relief effort, but exchange failures do not have an explanation.

- Sen's work does not explain the behaviour of many households faced by famine, who may go to considerable lengths to preserve their assets at almost any cost. The case of households which send some members to relief camps where mortality is known to be high, rather than further deplete their assets, or refrain from cutting down valuable trees or selling their last animals are well documented (e.g. see de Waal (1987) on Darfur). Indeed, people in relief camps, despite the degradation and health dangers, commonly hoard relief food in order to acquire further assets, or to delay the moment when they have again to live from productive assets. 
- The work does not satisfactorily explain what happens after a famine, when production and exchange relationships return almost to normal, although some households and communities remain much more vulnerable than others in ways production or exchange failures cannot satisfactorily account for.

- Sen's work treats war and civil disturbance as external to the model. Yet clearly civil war and other major disturbances are crucial to understanding vulnerability and famine in situations as different as Ethiopia, Sudan, Mozambique and Kampuchea.

Sen is aware of these problems. The main statement of his argument in Poverty and Famines tries to deal with them by broadening the field of concern to the concept of entitlements, rather than the narrower notion of exchange or terms of trade relationships. Entitlements, as defined by Sen, include all the productive resources owned by a household, including its labour power, and all its tangible assets; Sen also includes, although almost as an afterthought, social security provided by the state. However in his detailed analysis of cases, he deals almost entirely with production and exchange failures, concentrating on the relative role of each in the genesis of particular famines. Under the label of entitlements, he is in fact concerned with wage labour rates and livestock prices relative to grain prices.

As Sen himself states, his analysis is a sophisticated poverty analysis, and famine vulnerability is treated as synonymous with poverty. In his view (a) vulnerability to famine is a direct function of relative poverty, and

(b) relative poverty is a direct function of a household's ownership of tangible resources or endowments (labour, land, animals), and the rate at which it can exchange these for food.

We may ask whether either of these propositions is entirely true. Are the poorest people, and only the poorest people, the most vulnerable to famine? Is their poverty - defined in terms of the ownership (in a liberal, market economy sense of ownership) of mainly physical endowments - the main cause of their vulnerability? I think this may not be so, as I will attempt to show in the following argument. In particular, perhaps we need to introduce a better concept of risk - risk of future catastrophic collapse of consumption - into the definition of vulnerability.

\section{Assets}

Can we improve our understanding of vulnerability and famine by including in the model a more detailed analysis of the role of assets in a wide sense? This means separating out the terms of trade part of Sen's entitlement analysis, confining it to questions of exchange rate failure, and then analysing in more detail the other types of entitlement hinted at by Sen. By assets in this context I mean a wide range of tangible and intangible stores of value or claims to assistance which can be mobilised in a crisis A preliminary list of household assets relevant to famine vulnerability might be as follows, subdivided somewhat arbitrarily into investments, stores and claims:

\section{- Investments}

- human investments, including investments in education and health;

- individual productive assets, including animals, farming equipment, houses and domestic equipment, land, trees, wells;

- collective assets, such as soil conservation or water harvesting works, irrigation systems, access to common property resources.

\section{- Stores}

- food stores, granaries, etc.;

- stores of real value, such as jewellery, gold;

- money or bank accounts.

\section{- Claims}

- claims on other households within the community, for production resources, for food, labour or animals;

- claims on patrons, big men, chiefs or other communities for help in need;

- claims on government;

- claims on the international community.

Assets in this broad sense (including investments, stores and claims) are created when production leads to a surplus beyond immediate consumption requirements, and households use this surplus, willingly or unwillingly, to invest (including investment in better education or health), to build up physical stores of all sorts, and to 'invest in claims' by putting more resources into the community or government. This last category covers a wide range, including stock friendships, common among African pastoralists, whereby animals are loaned between kin and friends, other sorts of loans and gifts, traditional 
tribute and tax payments, contributions to community funds and resources, and the payment of taxes and other contributions to government.

Many of these assets are cashed in when households face a crisis: production assets are sold, granaries are emptied, jewellery is sold, bank accounts emptied, loaned animals recalled, labour debts called in and community support mechanisms activated. The sequence in which these assets are called in at different levels of crisis is an important theme for famine research. The sequence is mainly determined by the status of different categories of asset. Investments and stores are generally resources under the individual control of households, and can be mobilised by that household alone or in conjunction with others (in the case of collective assets); claims, on the other hand, refer to a range of wider social and political processes, whose activation depends on some level of collective decision.

Assets create a buffer between production, exchange and consumption. Production and exchange activities create assets, and in case of need assets can be transformed back into production inputs. Alternatively assets can be transformed directly into consumption, or indirectly through an exchange mechanism. Diagram 3 adds assets to the picture of casual pathways between production, exchange and consumption.

The notion of claims in this respect is shorthand for a variety of redistributive processes within smaller and larger communities, ranging from households and

Diagram 3

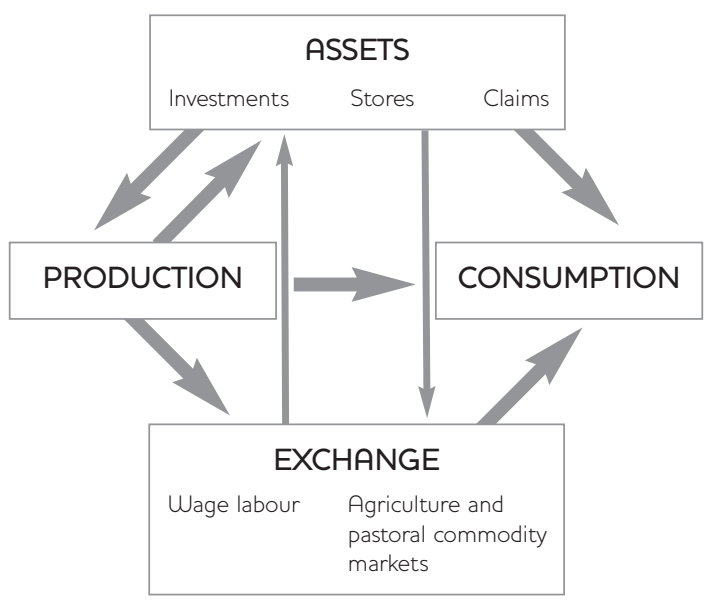

extended families, through shallow kinship groupings to major lineages, and up to the level of traditional and modern political formations. At the simplest level, groups of kin and friends help each other with food, labour or other resources. Such gifts and loans are made with varying expectations of reciprocity, but all involve an implicit recognition that membership of a community involves both an obligation to share resources, and a right to support from the community in case of need. In some cases this idea of reciprocal support goes so far as to throw doubt on the comparability of customary notions of private property with the classical liberal economy view, which is an important part of Sen's concept of entitlement. In many African pastoral economies, for example, the idea of private ownership of animals, especially large stock, is tempered by an ideology of collective clan property in the same animals, through which the clan as a whole has the duty and the power to redistribute animals from wealthier to needier people in a crisis.

At higher sociological levels, within both traditional and modern polities, the notion of claims merges with ideologies of community redistributive taxes (such as the zekkat now common in one form or another in Islamic Africa) designed to ensure survival of the poor in a crisis. The range of traditional institutions achieving the same end - collective work parties, shared meals, community granaries, rainmaking ceremonies or collective prayers in times of food shortage which include the redistribution of food or money from richer to poorer - is very large in Africa. At a different level, destitute members of one community may go to other communities to beg for work or charity. An undocumented and largely unanalysed aspect of recent famines is the way many slightly less poor rural communities have helped slightly poorer communities to survive - an act of apparent altruism explainable in terms of riskaversion in a longer perspective.

Claims on government are a particularly interesting case. In many types of rural society, payments or labour services to a dominant traditional political authority do create an expectation of a social contract, under which the political authority is expected to help in a crisis by redistributing food. The way this operated to avert famine has been well documented by Cissoko (1968) for the Songhay empire in the Niger river valley in Mali for the century or so before the chaos caused by the 
Moroccan invasion at the end of the sixteenth century. Traditional political authorities in many parts of the African dry belt continue to fulfil this function to a limited extent, and at an anecdotal level there are many stories of prosperous chiefs ruining themselves to keep their followers alive in the recent droughts; at the very least this suggests an ideology of sharing in a crisis.

This is not a plea for a pre-colonial 'merrie Africa' in which everyone shared and there was no famine. The model proposed here is close to Watts' (1983) reformulation, in respect of famine vulnerability in the Sokoto Caliphate in northern Nigeria, of the moral economy argument of Thompson (1971) and Scott (1976). The risk-avoidance strategies of precapitalist rural societies extend beyond agricultural and pastoral techniques into social and political mechanisms which include, at one level, more formalised expectations about the role of patrons or elite classes in ensuring peasant subsistence needs in a crisis. This normative subsistence guarantee spreads throughout the peasant universe in widening circles of responsibility, from the household, to extended kin, to village or pastoral clan patrons or superior classes, and ultimately to the state itself. This model does not suppose that villages or pastoral clans are corporate entities without class or status divisions; indeed, the moral economy emerges as the outgrowth of class struggle over the subsistence minimum and surplus appropriation. Governments, elites or the wealthy control the poor but depend on revenue derived from them. Within a common field of force, the moral economy is necessary to the survival of both ruler and ruled (Watts 1983: 104-9).

\section{Colonial and post-colonial governments in Africa} have not been very clear about their responsibilities in this respect. The growth of commodity production and market relations has strengthened food security in some aspects, but has also undermined the redistributive guarantees of the pre-colonial economy, replacing them with an uncertain market mechanism. As modern government has taken over the powers of traditional political authorities, it has expropriated the assets of rural people (including their stores, physical investments and collective investments). It has also imposed a substantial tax burden, offering in theory in return some social security in the most general sense. But although no colonial or post-colonial government in Africa would presumably deny a responsibility to keep its citizens alive in a famine, few would go as far as the 1880 Indian Famine Commission report, which stated:

... there can be no doubt that a calamity such as famine ... is one which a country such as India wholly transcends individual effort and power of resistance. It accordingly becomes the paramount duty of the State to give all practicable assistance to the people in time of famine, and to devote all its available resources to this end. (quoted in Drèze 1988: 13-14)

To what extent people feel they have a claim on the government in a crisis in unclear. Urban people certainly do, and successfully exercise that claim. Rural people seem much more ambiguous and varied in their responses: some do appear to call on the government not to let them starve, others do not. It would be an interesting research question to relate this to the tradition of effective central authority and high tax payments. Do communities, for example in the central Ethiopian highlands, where there is a long tradition of this sort, have a greater expectation of government support in a crisis? Do they 'call in their claim' more readily, abandoning efforts at selfhelp much earlier than communities where there is no such tradition, such perhaps, as Darfur (in terms of its expectation of the Sudan central government) or many Sahelian pastoral groups?

Reducing assets (including claims) makes households and communities more vulnerable, and the analysis could probably be extended to processes within households, particularly in respect of gender and intergenerational assets and claims. But this vulnerability will not be easily visible. Even tangible assets, such as granaries or livestock are often concealed to avoid expropriation by government, and many assets are intangible. People may survive for a year or more of crisis by cashing in physical assets and calling in claims, and then exhaust them so that their ability to survive appears suddenly to collapse, perhaps even at a time when production or exchange relations are improving.

The poorest people have fewest assets, so in general the poorest households reach the threshold of collapse much faster than others. Within socially stratified communities, low-status groups have fewest claims, and so may reach the threshold faster than their other asset holdings might predict. But low asset status is not necessarily synonymous with 
greatest poverty. The urban poor, and refugees in camps close to large towns, though often very poor, do seem able to exercise effective claims on the government for preferential assistance, in a way poor rural people generally cannot.

The way nearly destitute people try desperately to protect their assets in itself suggests something of their importance, both for survival in a crisis, and for recovery afterwards.

\section{Historical changes in vulnerability}

The asset status of rural communities does not remain static, and the way it evolves is a prime determinant of changing vulnerability. To illustrate this, I look at the case of Sahelian West Africa, shown in Diagram 4.

It is difficult to summarise complex historical trends into a single score, but we must try. Taking first the production box, and considering processes in the twentieth century only, we may make the following estimates. Climatic factors have been quite mixed, as has general ecological potential, with dry periods causing regression of vegetation and crops, and wet periods their recovery. Agricultural technology has probably on balance had a beneficial effect, although the pattern with crops and cropping is less clear, with some improved food crops but very uneven experience with cash crops. The possibilities for offfarm production activities have probably substantially improved. In summary, the production box probably deserves a mixed plus-minus mark.

In the exchange box, wage labour possibilities have probably substantially increased. The picture for commodity markets is more uneven. Pastoral markets have improved markedly, even though terms of trade remain vulnerable. In agricultural markets, cash crops have offered much wider incomegenerating opportunities, although prices have varied; food crop markets have generally declined. The exchange box also gets on balance a plus-minus mark, perhaps with more pluses than minuses.

The picture for the assets and claims box is more complicated still. Human investments, in health and education mainly, have probably improved, but most other investments have declined, especially collective investments in production-enhancing technologies and common resource management; investments deserves a plus-minus mark.
Stores and claims on the other hand, have declined in a fairly unequivocal way, with the exception of claims on the international community, which have only worked late and inefficiently. Both deserve negative marks.

The picture of historical changes in famine vulnerability, with the estimated marks for positive or negative changes in vulnerability, is shown below.

\section{Diagram 4}

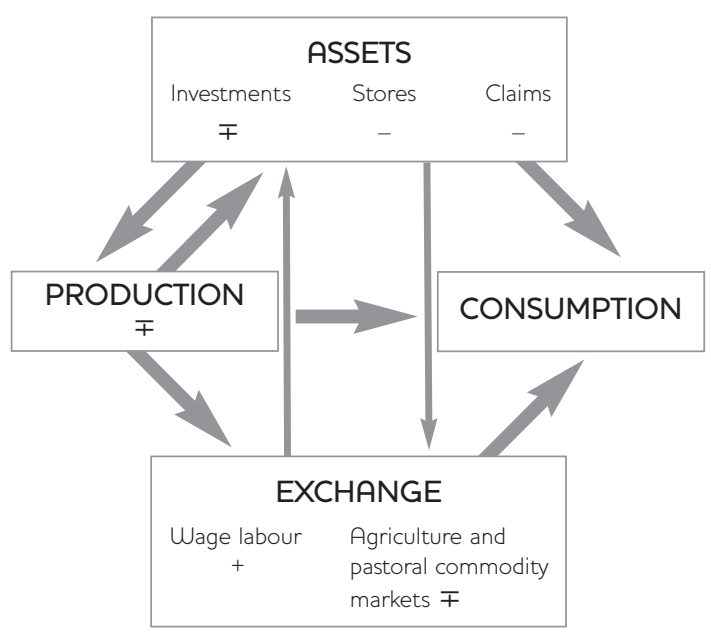

Such an exercise is very superficial, although no doubt it could be done more rigorously. It does, however, suggest that there has not been an equal increase in vulnerability in all boxes of the model. The situation has in fact been very mixed. However, if these marks make any sense, the assets box has seen a clear decline, meaning greatly increased vulnerability from this source. Is this a real marker to one of the reasons for increased vulnerability to famine in such Sahelian populations?

Put another way, has the increased economic integration of the traditional Sahelian economies with wider markets, and the corresponding decline in local circulation of goods and services, achieved important economic benefits for most producers, but at the cost of significant increases in two sorts of vulnerability: increased dependence on market transactions with corresponding vulnerability to terms of trade failure, and a reduction in physical assets and effective local claims, inadequately compensated by a non-functional social contract with central government? 


\section{Conclusions for famine policy}

The analysis of assets and claims does appear to add something to our understanding of famine vulnerability in addition to the insights from analysis of production and exchange failures. It gives a clearer idea of the way famine is generated, who suffers most, the chronology of economic and social collapse, and the thresholds at which different groups become utterly destitute. It explains why war and civil unrest, the most obvious break in the moral economy and abrogation of claims by government, are a crucial cause of vulnerability. It also explains more about household and community strategies to avoid famine and rebuild a life afterwards. It answers most of the questions raised earlier about entitlement theory.

Perhaps it also helps us to ask more appropriate questions about the apparent difference between recent African and Indian famines. Those who are most vulnerable to famine in India (especially agricultural labourers and petty commodity and services producers) are not necessarily the most vulnerable in Africa (with the possible exception of Sudan). Income failures for such people seem the most important cause of Indian famines. Is this true of Africa? Are assets more important to the survival of rural people in Africa than they are in India, and asset failure thus catastrophic? Are claims to community support more effective in Africa most of the time, but the situation resultingly catastrophic when such support breaks down?

Perhaps most significantly, does the Indian government now accept claims on it by starving people, as the 1880 Famine Commission urged it should, and so do something about them (through famine codes, employment guarantees, fair price shops, cattle camps), in a way that African governments do not?

If this way of looking at famine vulnerability has some virtue, it has clear implications for policy. $A$ policy to reduce vulnerability would not then necessarily be the same as a policy against poverty, although it would have much in common, nor would it be the same as a food policy, although a food policy should include a policy on reducing vulnerability. A vulnerability policy should include actions in the fields of production, exchange and assets. Some potential policy areas would include:

- Early warning. Low asset status in rural communities would be a particularly good indicator of vulnerability.
- Exchange interventions. Interventions in the wage labour market (through employment guarantees) and in commodity markets (through price support) would reduce vulnerability.

- Improving assets and claims. The main problem is how to rebuild the asset status of rural communities in both tangible and intangible assets. Making it easier for people to invest in health and education would help - few households with one educated member starve, perhaps precisely because such people can effectively activate claims for assistance from the government. Government can assist recapitalisation and collective investments in productive technologies. Cereal policy, instead of emptying household and community grain stores, should help keep them full; the same should apply to bank accounts, other stores of value, and perhaps even to new forms of insurance. Policy should revitalise and strengthen systems of claims and responsibilities, starting with a clearer and more effective view of government responsibility and the legitimacy of claims against it in a food crisis, but extending to and including systems of local community support.

There are also lessons for emergency relief and food aid. Rehabilitation of rural economies after famine means not only reinstating their production status, and ensuring that their exchange and terms of trade relations are acceptable. It also means the much longer tasks of rebuilding their asset status, and their own social frameworks through which claims and asset sharing are organised. At present, relief tends to undermine local organisational capability by imposing procedures dictated by an understandable desire for efficiency, donor accountability and shortterm cost-effectiveness. But local community structures are bypassed whenever relief food is distributed to those who qualify on a nutrition status criteria, or food-for-work is organised in labour gangs for projects decided and administered by the relief agency. If local organisational capacity is an important resource in making communities less vulnerable, actions such as these, even if they save lives in the short run, contribute to greater vulnerability in the long run. Food aid in particular, in relief programmes, should be used not only to save lives but also to protect assets; in rehabilitation programmes, food aid should be used more explicitly to rebuild household and community assets, and to rebuild local organisational capability. 


\section{References}

Cissoko, S.M. (1968) 'Famines et Épidémies à Tombouctou et dans la Boucle du Niger du XVle au XVIIle Siecle', Bulletin de l'IFAN 30, B(3): 806-21 de Waal, A. (1989) 'Famine Mortality: A Case Study of Darfur, Sudan 1984-5', Population Studies 43 de Waal, A. (1987) Famine That Kills: Darfur 1984-5, London: Save the Children Fund

Drèze, J. (1988) Famine Prevention in India, Discussion Paper 3, Development Economics Research Programme, London School of Economics Scott, J. (1976) The Moral Economy of the Peasant, New Haven: Yale University Press
Sen, A. (1981) Poverty and Famines: An Essay on Entitlement and Deprivation, Oxford: Clarendon Press

Swift, J. (1985) Planning Against Drought and Famine in Turkana, Northern Kenya, Nairobi: Oxfam and Turkana Rehabilitation Project

Thompson, E.P. (1971) 'The Moral Economy of the English Crowd During the Eighteenth Century', Past and Present 50

Watts, M. (1983) Silent Violence: Food, Famine and Peasantry in Northern Nigeria, Berkeley: University of California Press 